\title{
Teaching Evolution with Historical Narratives
}

\author{
Esther M. van Dijk • Ulrich Kattmann
}

Published online: 2 April 2009

(C) Springer Science + Business Media, LLC 2009

\begin{abstract}
This paper focuses on evolution as a unifying theme in biology education. Our aim is to argue that the different topics taught in secondary school biology classes should be enriched with and linked together by means of accounts of the history of life. We named this approach a "natural history perspective" on biology education. An essential aspect of the natural history perspective is the claim that evolutionary history forms the context for the development of an understanding of evolutionary processes. While there are some indications that a natural history perspective can function as a context for understanding micro-evolutionary processes, more research is called for.
\end{abstract}

Keywords Evolutionary theory - Narrative explanation . Historical narrative $\cdot$ Unifying theme $\cdot$ Natural history

Evolutionary history

\section{Introduction}

Evolution is the core theory of the biological sciences, and as such, evolutionary biology makes important contributions to other fields of biology, such as developmental biology, physiology, and ecology. In addition, evolutionary biology makes important contributions to pressing societal

E. M. van Dijk $(\bowtie) \cdot U$. Kattmann

Didaktisches Zentrum, Carl von Ossietzky University Oldenburg, 26111 Oldenburg, Germany

e-mail: e.van.dijk@uni-oldenburg.de challenges concerning the environment, diseases, and food production (Futuyma 1999). As Joseph Schwab put it in the first Biology Teachers' Handbook (BSCS 1963 p. 32): "Evolution, [...], forms the warp and woof of modern biology."

Within secondary school biology curricula, evolution is and has been acknowledged to be a central and unifying theme in the curriculum. For example, in 1959, the Biological Sciences Curriculum Study (BSCS 1963, 1993) was established by the American Institute of Biological Sciences with the aim of developing a more coherent approach to the teaching of biology. The structure of the teaching materials developed by the BSCS was based on nine unifying themes, one of which was evolution. Joseph Schwab (BSCS 1963) described that in the BSCS teaching material, evolution is treated in three different ways. First, there are specific chapters on evolution as the history of living things. Second, there are specific chapters on evolution as a process. Third, evolution, either as history or as process, is interwoven in all other chapters, where it has a place, for example, in the discussion of cell chemistry, ecology, taxonomy, and so on. Evolution, thus, is considered to be a recurring topic within the curriculum and, moreover, a topic that should be developed through the years.

In more recent efforts to enhance the coherence of the curriculum, a variety of unifying themes have been chosen to connect the various concepts and processes within biology. The Dutch biology curriculum reform project (Boersma et al. 2007), for example, has chosen a number of system concepts that can be applied to all biological systems on all organizational levels: the biological unit, self-regulation/self-organization, interaction, reproduction, 
and evolution. In the German Standards for Biology Education (KMK 2004), the three basic concepts are: system, structure/function, and development. The basic concept of "development" is subdivided into two concepts: "individual development" and "evolutionary development." These recent examples seeking to enhance the coherence of biology education also view evolution as a central theme.

In present-day biology teaching, however, evolution is still mostly taught as only one topic among many. Students often receive little exposure to this central concept of biology, notably within the USA (National Academy of Sciences 1998), the Netherlands (KNAW 2003), Germany (Baalmann et al. 1999), and Sweden (Zetterqvist 1999). Furthermore, the focus of evolution education is mainly on micro-evolutionary processes; too little attention is given to macro-evolutionary processes and the history of life (Catley 2006; Kattmann 1995).

In 1973, the biologist Dobzhansky (1973) argued in an article in the journal American Biology Teacher that: "Nothing in biology makes sense except in the light of evolution." This citation is often understood in the sense of: Nothing in biology makes sense except in the light of adaptation. However, Griffiths (2009) observed that this perspective on evolution is a long way from what Dobzhansky meant: "for Dobzhansky himself, biology makes sense in the light of evolution because it only makes sense if life on earth has a shared history." This paper, then, focuses on evolution as a unifying idea in biology education; more specifically, it focuses on evolution in the sense of evolutionary history. We regard evolution not only as a unifying theme among others but also as the one

\footnotetext{
"The position of the concept of "evolution" as a subconcept of the concept "development" is problematic. Evolution is not a form of development in the biological sense, and use of the term "evolutionary development" should, therefore, be avoided. The word evolution comes from the Latin "evolvere" which means "to unroll," "to unfold," to reveal, or to manifest hidden potentialities (Futuyma 2005). It was first used in biology to describe the development of the embryo: "Early embryologists believed that the growth of the organism was no more than an expansion of a preexisting miniature, a process which fits the literal meaning of evolution" (Bowler 2003 p. 8). Herbert Spencer was the person who popularized the term evolution, using it for all sorts of developmental processes that lead from the simple to the more complex, among others, individual development and the development of life on earth (Jablonka and Lamb 2005). Today, the general meaning of the term "evolution" (i.e., not limited to the biological context) is simply "change." In biology, however, "evolution" has a much more strict meaning; biological evolution is defined as change in the properties of groups of organisms over the course of generations (Futuyma 2005). Since Darwinian evolution is not the unfolding of hidden potentialities, it should not be called development.
}

central idea that interconnects different topics within biology education. Our aim is to argue that the different topics within biology education should be enriched with and linked together by means of accounts of the history of life. We named this approach a "natural history perspective" on biology education. An essential aspect of the natural history perspective is that evolutionary history forms the indispensable context for understanding evolutionary processes. This does not mean, however, that other topics within biology education such as genetics, ecology, cell biology, etc. are of minor importance. We only aim to suggest that a topic like, for example, the cell can be enriched with a discussion of the endosymbiosis hypothesis (Margulis 1981), which offers a historical account of how the prokaryotic ancestors of chloroplasts became organelles in eukaryotes.

The use of the term "natural history" requires some explanation. A quotation from the Origin of Species (Darwin 1964 p. 485-486) expresses why the name "natural history perspective" has been chosen:

[W] hen we regard every production of nature as one which has had a history; when we contemplate every complex structure and instinct as the summing up of many contrivances, each useful to the possessor, nearly in the same way as when we look at any great mechanical invention as the summing up of the labour, the experience, the reason, and even the blunders of numerous workmen; when we thus view each organic being, how far more interesting, I speak from experience, will the study of natural history become!

Darwin observed that the study of natural history has a historical dimension. Biodiversity should not be studied as it is - a static natural history - but should include accounts of the ancestral history of organisms - a truly temporal history. Although today, the term "natural history" is still often used in the sense of a static natural history, we name our approach "natural history perspective." We want to retain the term "natural history" because of the many contributions that natural history, the knowledge of biodiversity, made and still makes to the study of evolution (see Futuyma 1998).

In "The Natural History Perspective," we will develop this natural history perspective further. The natural history perspective presented here focuses on explanations of evolutionary history: narrative explanations or historical narratives (Goudge 1961; Gould 1989; Mayr 1982). We suggest that the integration of these historical narratives in secondary biology education can provide a coherent context for the teaching of evolutionary theory. In "Teaching the 
History of Life," two examples of teaching units will be presented in order to illustrate what such a natural history approach might look like. Questions for future research that spring from the presented discussion of the natural history perspective will be discussed in Prospects for Further Research.

\section{The Natural History Perspective}

\section{What? and How Come?}

Ernst Mayr's three questions used in classifying the different biological disciplines form a good structuring device for explaining the approach to biology teaching that we want to present in this paper. According to Mayr (1997), biology tries to answer three different kinds of questions: What?, How?, and Why? What-questions were traditionally answered within the field of natural history that focused on the description of the existing diversity of natural phenomena like minerals, fossils, plants, and animals (for a history of natural history, see Jardine et al. 1996). Research in functional biology, for example, physiology deals primarily with How-questions. How-questions concern the analysis of processes, from the molecular level up to organisms. For example, how does the process of photosynthesis work in plants? It could be said, in contrast to how Mayr defines How-questions, that the field of evolutionary biology is also interested in How-questions concerning the microprocesses of evolution that can be studied today (for example the study of natural selection in Darwin's finches by Grant and Grant as described in Weiner 1994). However, Mayr (1997) emphasized that evolutionary biology is, in the first place, concerned with answering Why-questions in the sense of "How come?" These Why-questions do not ask for a final cause, a preconceived ultimate goal. Instead, these "Why-questions deal with the historical and evolutionary factors that account for all aspects of living organisms that exist now or have existed in the past" (Mayr 1997 p. 115). For example, how come plants have chloroplasts that enable them to photosynthesize and animals do not?

A recent report titled "Science education in Europe: critical reflections" (Osborne and Dillon 2008 p. 15) stated that: "school science begins with foundational knowledgewhat a cell consists of [...]-ideas which appear to most children as a miscellany of unrelated facts." It is observed that school science fails "to generate a sense of anticipation that accompanies an unfolding narrative. That is, $[\ldots]$ beginning with what might be called overarching questions." Indeed, much of secondary biology education is concerned with foundational knowledge concerning biological structures and their functional properties, for example the human digestive, circulatory and respiratory systems - that is, on issues in the domain of Howquestions. More importantly, it appears that the one overarching question concerning the diversity of living organisms and how this diversity came about gets too little emphasis. In order to answer this question, more attention should be given to What- and Why-questions in biology education. We do not suggest that What- and Why-questions should be stressed at the expense of Howquestions or that these questions can be treated separately. On the contrary, we think that these questions should be implemented in biology education in a balanced and integrated way, which is not what is happening in education today.

Introducing historical narratives in secondary biology education can be a first step toward teaching evolution as the unifying theme that it truly is. There are different kinds of historical narratives, one prominent example being is the tree of life. The tree of life can be seen as the backbone of biology education. The tree of life or phylogenetic tree ${ }^{2}$ not only represents the objects of study themselves but also shows how they are related in time. Since the publication of Darwin's Origin of Species, classification of organisms is often seen as portraying the real history of life on earth (Futuyma 2005 p. 22). Therefore, the tree of life is not only the answer to a What-question but also constitutes part of the answer to a Why-question: the phylogenetic tree tells a story of how life evolved on earth. In recent years, a growing number of articles have been published lamenting the lack of "tree thinking" within biology teaching (Baum et al. 2005; Gregory 2008; Meir et al. 2007; Novick and Catley 2006, 2007). The authors of these studies observed that phylogenetic trees have become increasingly important in biological research: "For example, the case of HIV/ AIDS, where phylogenies have been used to identify the source of the virus, to date the onset of the epidemic, to

\footnotetext{
${ }^{2}$ A remark by an anonymous reviewer indicated that the usage of the terms "cladogram" (which Hennig called phylogenetic diagram) and "phylogenetic tree" causes much confusion. Both cladograms and phylogenetic trees are branching diagrams that, however, represent different relations between taxa. Cladograms represent sister-group relations (Hull 1988 p. 136) and none of the included taxa are recognized as ancestral taxa. Phylogenetic trees, however, also include ancestral taxa and ancestral relations between taxa. Cladograms can be used to generate hypotheses about possible ancestral relations that can be tested by other forms of evidence such as stratigraphical information (Skelton 1993 p. 541-542). We refer to phylogenetic trees instead of cladograms because phylogenetic trees have an implicit time axis whereas cladograms do not.
} 
detect viral recombination, to track viral evolution within a patient, and to identify modes of potential transmission" (Baum et al. 2005 p. 979). The authors further observed that although trees have become an important instrument in biological research, tree thinking has not made any significant inroads into science teaching. Their call for more tree thinking in science teaching strengthens our proposal for a natural history perspective in science education.

However, there is more to evolutionary history than the history of ancestry and descent of species. A phylogenetic tree tells only a part of the story of the history of life on earth: it depicts the ancestor-descendant relationships between species, but it does not represent the adaptive history of individual species. That is, a tree does not contain any information about which adaptations occurred in which environments, at which locations, and at which times. Therefore, we want to suggest a broader approach to evolutionary history in science teaching: besides trees, other more detailed historical narratives can make students aware of the history of life and can help them to understand evolutionary processes better. For example, instead of only asking "How does the human eye work?" we should also ask how this specialized organ has evolved and why model organisms like mice can be used for improving our understanding of human eye malformations.

Biologists study among other things, living organisms, their physiology, and how they develop. However, Goudge (1961 p. 62) reminded us that: "organisms are literally historical creatures. Their history is built into them. Hence no scientific account of organisms can be satisfactory if it abstracts them from their concrete history." Thus, no scientific explanation of the organisms living today is complete without the inclusion of their history. Since it is the field of evolutionary biology that studies the processes that lead to organic diversity and that concerns itself with the study of the history of present-day organic diversity, evolution is a central theme in the study of biology.

This natural history perspective appears to be missing in biology teaching: historical narratives have been given little attention in biology education; the Why-question, an essential component of evolutionary biology, is often forgotten when a phenomenon is discussed. If we want to improve this situation and integrate narrative explanation in the teaching of biology, we need to be clear about the problems that might arise and about what we might gain by such an approach. The epistemological value of narrative explanations will therefore be discussed in the next section.

\section{Narrative Explanations}

The explanations of particular events in evolutionary history are based on characteristics of organisms living today and in the past. Molecular data and phenomena like homologies (more precisely synapomorphies), vestigial organs, and biogeography provide the support for the hypothetical ancestor-descendant relationships between species represented by the phylogenetic tree. Paleontological and geological evidence provide further support for the reconstruction of the history of life. Based on this evidence, narrative explanations of unique historical phenomena such as major transitional events, for example, the transition from amphibians to land dwellers can be described. A narrative explanation aims to explain these unique events by describing a sequence of causally related events, which have led to a certain outcome (Goudge 1961; see also Nagel (1961) and Salmon (1989)). Gould (1989 p. 283) formulated a similar view on historical explanations in his book Wonderful Life. He stated that: "historical explanations take the form of narrative" describing a narrative as: "E, the phenomenon to be explained, arose because D came before, preceded by $\mathrm{C}, \mathrm{B}$, and $\mathrm{A}$. If any of these earlier stages had not occurred, or had transpired in a different way, then E would not exist [...]. Thus, E makes sense and can be explained rigorously as the outcome of A through D."

An important element of Gould's view of evolutionary biology as a historical science is the notion of contingency (See also Beatty's work on his Evolutionary Contingency Thesis that aimed to further elaborate and defend Gould's thesis, 1995). Gould (2002 p. 1333) explained that:

[A] narrative or historical style that explicitly links the explanation of outcomes not only to spatiotemporally invariant laws of nature, but also, if not primarily, to the specific contingencies of antecedent states, which, if constituted differently, could not have generated the observed result. As these antecedent states are, themselves, particulars of history rather than necessary expressions of law, and as subsequent configurations can cascade in innumerable directions, each crucially dependent upon tiny differences in the antecedent states, we regard these subsequent outcomes as unpredictable in principle [...] however fully explainable they will become, at least in principle, after their occurrence as the single actualized result among innumerable unrealized possibilities. 
Gould suggested that the outcomes of evolution cannot be predicted from general principles like natural selection and laws of nature alone because small changes in preceding events could lead to a different outcome. Gould (1989) expressed this in his "tape of life" metaphor: if we rewind the tape of life and replay it, the outcome would be entirely different. The outcome can only be explained after the fact in the form of a narrative, which contains law-like principles and, most importantly, historical particulars. For example, modern whales seem to be fully adapted to living in water. However, the fact that modern whales have a rudimentary pelvis can only be explained by including the historical particulars - the details of the explanation, such as the existence of extinct whales, like Basilosaurus, with leg bones, which paleontologists have found (see Thewissen and Bajpai (2001) for a general outline of whale evolution).

Whereas the historical sciences focus on detailed accounts of complex, unique, historical phenomena, most contemporary natural science focuses on general principles instead. The traditional and idealized covering-law model of Hempel (1963) says that an event $\mathrm{E}$ is explained by showing that it can be deduced from the particular circumstances or initial conditions and one or more universal laws. For example, the mythical event of an apple falling on Newton's head is explained by a general principle: Newton's law of gravitation, which describes the gravitational force between two masses based on the initial conditions that describe the special circumstances of this particular event, that is, the actual place and objects involved. By citing universal laws, a scientific explanation tries to describe why an event necessarily happened. The explanatory force of this account lies in the described law (Hull 1992). In contrast, a historical narrative can tell us why an event actually or possibly happened (O'Hara 1988). If we had complete information, a historical narrative could explain why a certain historical event actually occurred. However, in most of evolutionary history, we do not have enough information about the environmental conditions in which adaptations might have arisen. As Hull (1992, p. 71) put it, "in evolutionary biology $[\ldots]$ too many contingencies are too important." $\mathrm{He}$ therefore argued that the explanatory force of a historical narrative lies in the initial conditions. The general laws are relevant, according to Hull, because they form the theoretical context for the description of the development of the historical entities. Take, for example, the extinction of the non-avian dinosaurs at the end of the Cretaceous period. A number of causes have been suggested to explain this mass extinction event, for example, plate tectonic change or an asteroid impact. The impact theory describes which physical evidence exists for the actual occurrence of an asteroid impact on the Yucatán peninsula at the end of the Cretaceous period. Based on this evidence, Alvarez et al. (1980) hypothesized how this impact caused the Cretaceous/Tertiary $(\mathrm{K}-\mathrm{T})$ mass extinction: the impact created a cloud of dust, which blocked the sun and led to the break-up of food chains and ultimately a mass extinction. A single event, the $\mathrm{K}-\mathrm{T}$ mass extinction, is, thus, explained by describing a possible sequence of causally related events with as much detail as possible and, of course, within the boundaries of natural laws.

The purpose of this brief discussion was to present a short overview of the problems - and their roots in the traditional views of the nature of explanation - that are associated with the use of historical narratives in science. However, for biology education, it is important to realize that, these problems notwithstanding, historical narratives do have an epistemic value. It is clear that a historical narrative, although it is often far from complete, can contribute to a better understanding of historical events. To understand the characteristics, diversity, and distribution of organisms living today, it is necessary to have some knowledge of their history. The required historical narratives give an account of the ancestral history of living organisms based on a detailed description of the particular circumstances in which ancestors of today's organisms evolved. Whenever possible, this should include explicit reference to laws of nature. Historical narratives provide explanations of biological facts; for example, why the non-avian dinosaurs became extinct or the fact that all modern tetrapods have a fivedigit limb structure.

In the next section, we will illustrate the proposed natural history perspective on the basis of two teaching units that were published in a German journal for secondary biology teachers (Baumann et al. 1996; Sander et al. 2004).

\section{Teaching the History of Life}

\section{The Tree of Life}

An important issue in science teaching that we believe teachers and teacher educators should be aware of, is that "just as beginning students in geography need to be taught how to read maps, so beginning students in biology should be taught how to read trees and to understand what trees communicate" (O'Hara 1997 p. 327). A growing number of studies discuss students' difficulties with tree 
thinking and classification (Baum et al. 2005; Gregory 2008; Meir et al. 2007; Novick and Catley, 2006). We will not discuss this literature here. Our goal is to illustrate the proposed natural history perspective with the help of a teaching unit on classification that was developed for 1113-year old secondary school students (Baumann et al. 1996; see Fig. 1 for a step-by-step description of this teaching unit).

The teaching unit, entitled "From water to land and back," is based on research into students' conceptions of classification. If young students can choose freely, they often use habitat and way of movement as criteria to classify organisms; for example, young students often think that whales are fish and not mammals, as both whales and fish live in water and have similar ways of swimming (Kattmann 2001). The difference between the scientific way of classification and the everyday classification by students is that there is only one criterion for classifying organisms scientifically, namely the most recent common ancestor (MRCA). The concept of MRCA is one of the evolutionary-history concepts that appears to be difficult to understand for students. For example, students harbor a serious misunderstanding concerning human ancestors: the conception that humans evolved from chimpanzees or gorillas (Alters and Nelson 2002).

The scientific classification of organisms is usually intended to represent the history of evolution (Futuyma 2005 p.22). This means that organisms are not classified into the same group because of the characters that they have in common but because they have a most recent
Fig. 1 "From Water to Landand Back": A step by step description of a teaching unit on classification developed in the context of the natural history perspective for 11 to 13 year old students

\section{From Water to Land - and Back}

A teaching unit for 11-13 year old students (based on Baumann et al., 1996)

\section{Vertebrates and their habitat}

Step 1. Which animals are vertebrates and which characteristics do they have in common?

(Study materials: skeletons, pictures)

Step 2. How can the vertebrates on worksheet 1 be grouped?

(Study materials: worksheet 1 shows 17 pictures of different vertebrates.)

A historical narrative explains why the habitat of modern representatives of species is an indication for classification. The students are being told the story about how the vertebrates evolved, i.e., that terrestrial vertebrates evolved out of a parent population that inhabited the water.

(The students work in tandem on the classification of vertebrates based on their living environment: water, water-land, land and land-air. Problematic cases like crocodile, snake, tortoise, and newt are being set apart.)

\section{Indications of history}

Step 3. What is the difference between a newt and a lizard?

(Study material: worksheet 2 describes the development of two similar looking animals, a newt and a lizard.)

Where do newts and lizards lay their eggs?

(The term "amphibian" is introduced for the newt, a water-land organism that lays its eggs in the water)

Step 4. Are crocodiles, snakes and tortoises amphibians?

(The students collect information on the development of the different organisms.)

Step 5. Return to the classification of Step 2: Do all terrestrial animals lay eggs?

(The statement "mammals do not lay eggs" can be discussed with the help of the platypus - a representative of the monotremes - a mammal that lays eggs in the same manner as reptiles. Worksheet 3 describes the platypus, its way of living and its development. Furthermore it should be discussed that mammals are viviparous and that the egg and embryo develop inside the body. Other characteristics of mammals, hair and mammary glands, are introduced as indications of their common ancestry. It is recognised that classification is based on common descent and not on common characteristics.)

\section{From land to water}

Step 6. Return to the classification of Step 2: Are all water animals fish?

(Study material: worksheet 4 describes the reproduction and development of the whale. Worksheet 5 describes the historical narrative about how the ancestors of modern whales returned to the sea. 
common ancestor. But sharing the same characters can be a good indication of common ancestry. Sober (1988 p.x) gave a basic description of the method for classifying the diversity of organisms in his book Reconstructing the Past:

If the organisms we now observe are a consequence of descent with modification, then the resulting tree of life will be such that some species are closely related while others are related more distantly. We do not observe this branching process directly; it is not by direct inspection that we know that human beings and chimps are more closely related to each other than either is to snakes. Rather, evolutionists seek to recover the relationships engendered by this branching process by examining its end product. We observe species and their characteristics; we begin with these similarities and differences and hope to use them as evidence supporting some hypotheses of relationships and disconfirming others.

That is, the principal criterion for classifying organisms in biological science is common ancestry: organisms that share a most recent common ancestor are to be grouped together.

Students need to learn how to use MRCA as the criterion for classification. The first step in classifying organisms is to distinguish homologies (characters shared by two or more species due to their common ancestry) from analogies (characters shared by two or more species, but not due to their common ancestry; Ridley 1996). Both types of characters could be seen as adaptations to the environment, but only homologous characters indicate phylogenetic relationships. For example, the wings of birds and bats are analogous characters. They are both used for flying, but they are structurally different and, hence, do not trace back to a particular character of a most recent common ancestor of bats and birds.

The teaching unit aims to show that organismal characteristics are possible indications for the history of evolution. The concept of "common ancestor" is introduced to the students as the criterion for classification. A historical narrative explains why the habitats of modern representatives of particular species are an indication for classification. The students are being told the story about how the vertebrates evolved, i.e., that terrestrial vertebrates evolved out of a parent population that inhabited the water. The place where eggs are laid (on land or in water) is introduced as another indication for classification of the vertebrates in the three groups: water (fish), water-land (amphibians), and land (the Amniota: "reptiles," birds, and mammals). The main aim of the teaching unit is to make students understand that the characteristics of organisms, their skeletons, habitats, and ways of giving birth are indications of their history and, through this, how the organisms are related to each other. The whale is included as a last problem case because it is difficult to classify without the MRCA criterion. For students to understand that a whale is a mammal, they need to be told the history of how whales evolved (students who know that whales are mammals have difficulties with its aquatic mode of life and characterize them as "mammal fishes"). The historical narrative about how the ancestors of modern whales returned to the sea explains why the whale lives in water but gives birth to live young and breathes air. The historical particularities provide a possible explanation for this phenomenon.

The historical explanation of these unique evolutionary events, how the amphibians evolved and how the ancestors of the whales adapted to living in water, provides students with a context for thinking about the diversity of organisms, their common characteristics and the evolutionary process. We need to tell these historical narratives not only to illustrate how organisms in the past have adapted to their environment but also how the preceding stages have influenced the result of evolution - the organisms living today.

\section{Earth History and Socio-Scientific Issues}

The second illustration of our natural history perspective is based on the teaching unit entitled "Where does oxygen come from?" (Sander et al. 2004; see Fig. 2 for a step-by-step description of this teaching unit). This teaching unit links the history of photosynthetic organisms to the history of the atmosphere and to the debate on climate change. The teaching unit shows that the inclusion of narrative explanations in biology education can contribute to an understanding of socio-scientific issues.

Students often think that today's forests should be protected because they are the source of the oxygen that we need for living. This view corresponds with the facts to the extent that the earth's oxygen pool remains intact because of the equilibrium between photosynthesis and respiration: carbon dioxide and water combining through photosynthesis to form carbohydrates and oxygen one way, while the respiratory reaction works in the other way. While the biosphere is in a steady state, no oxygen surplus or deficit results. The earth's oxygen pool, however, is the result of a historical disequilibrium between photosynthesis and respiration. For example, during the Carboniferous period, the terrestrial biomass increased, and some of this biomass became buried, giving rise to the vast Carboniferous and Permian coalfields. With so much organic material taken out of the carbon cycle, significant oxygen surplus was left behind in the atmosphere. However, the first major contribution to the development of the oxygen surplus in 
Fig. 2 Where Is Oxygen Coming From? A step-by-step description of a teaching unit on ecology developed in the context of the natural history perspective for 13-to-16-year-old students

\section{Where does oxygen come from?}

A teaching unit for 13-16 year old students (based on Sander et al., 2004).

\section{Why should we protect the forest?}

Step 1. Why should we protect our forests?

The students' answer, that forests produce oxygen, is contrasted with the statement by Lovelock that the value of tropical rainforests is not that they produce oxygen.

(Study material: worksheet 1 shows a schematic biochemical cycle. The students learn that only when biomass is deposited an oxygen surplus develops.)

\section{Where does oxygen come from?}

Step 2. Why weren't the Carboniferous forests broken down (oxidized)?

(Study materials: worksheet 2 describes a historical narrative on how the imbalance between build-up and break-down of biomass came about in the Carboniferous period.) Step 3. Return to worksheet 1 and explain why the development of coal resulted in an oxygen surplus in the atmosphere?

Step 4. Is biomass deposited today like in the Carboniferous period?

(Study materials: a diagram of the historical development of the oxygen content of the atmosphere.)

\section{A world without plants}

Step 5. What would happen with the oxygen surplus if we destroyed all the plants on earth? How long can we live on the available oxygen supplies? Why should we protect the forests? the earth's atmosphere was produced by photosynthetic microorganisms, prokaryotic algae, some two billion years ago. The initial oxygenation of the atmosphere was due to the burial in marine sediment of some of the carbohydrate, leaving behind an oxygen surplus. The subsequent rise of the oxygen level in the earth's atmosphere occurred over millions of years until it reached today's value (Cowie 2007).

In the teaching unit, a historical narrative explains how the earth's oxygen pool came about because of the deposition of biomass in the earth's history. The consequential diminished role of the today's forests as a source of oxygen leads to a discussion of other reasons for protecting forests. This example shows that the natural history approach should not be limited to phylogeny and the organismal perspective but should be extended to the history of Bioplanet Earth (term introduced by Kattmann 2004). For our understanding of complex phenomena like climate change, it is especially important that we realize that biogeochemical cycles have a history related to organismal evolution.

\section{Prospects for Further Research}

\section{Different Perspectives on Understanding Evolution}

Research has shown that students often leave school without having acquired a scientifically valid conceptual framework of evolutionary theory (Alters and Nelson 2002). As the theory of evolution is a conceptually complicated theory, there exists a great variety of - often flawed - conceptions of the nature of biological evolution and its different elements among the general public, high school and university students and teachers. Much research has been undertaken to uncover and describe these prescientific conceptions. For example, conceptions concerning variation and adaptation appear to spring from a predisposition of students to essentialist and teleological ways of thinking (see Gelman (2003) with respect to essentialism; Kelemen (1999, 2003), Poling and Evans (2002) with respect to teleological thinking). The proposed natural history perspective takes the students' prescientific conceptions as the starting point for teaching (see the teaching units in "Teaching the History of Life").

Additionally, it has been suggested that the difficulty with understanding evolutionary theory is related to the understanding of the nature of science. Dagher and Boujaoude (2005 p. 379) observed that: "students' conceptual difficulties $[\ldots]$ are generally accompanied by a limited understanding of the nature of science." And Rudolph and Stewart (1998 p. 1076) observed that: "problematic has been the tendency for science educators to use the physics model [that is focussed on laws] in the development of curriculum intended to address general issues concerning the nature of science, thus perpetuating a misunderstanding of scientific method that may foreclose the effective learning of evolutionary biology." The proposed natural history perspective 
aims to make a contribution to the development of students' views on the nature of science through the inclusion of historical narratives in biology education, thus, showing the role of historical explanations in biological science.

The essential aspect of the natural history perspective is the view that the teaching of biology and especially the teaching of the micro-evolutionary processes of evolution should be embedded within the context of a historical narrative. Studies on understanding evolutionary theory have focused on the micro-evolutionary processes, and although there is a growing attention for tree thinking, we still find that the "history of life" aspect deserves more attention. Catley (2006 p. 779) made a similar observation: "it is not sufficient that students learn the nuts and bolts of genetics and natural selection in a vacuum and be expected to 'understand evolution' in its entirety." We should, therefore, ask ourselves in how far the problems with understanding the evolutionary process are caused by a lack of attention to the "history of life" in teaching.

\section{The Role of Historical Narratives in Teaching}

Although there is a lack of studies on this matter, there are some indications that knowledge of evolutionary history can be helpful to develop an understanding of evolution. Evans (2000), for example, studied children's ideas of the origin of biological species. In her study, Evans (2000) showed that there is a positive correlation between the frequency with which children use evolutionary explanations for the origin of species and their natural history knowledge, in particular of fossils, adaptation, and deep time. The measure of the children's understanding of natural history knowledge was based on items that were judged to be critical in the development of an understanding of evolution: fossils (and dinosaurs), adaptation (an understanding that species fit their habitats), and deep time (an understanding that the earth is very old). These results might be interpreted as a first indication for the importance of evolutionary history knowledge as a context for the development of evolutionary explanations.

A second indication can be deduced from the research on the understanding of the concept of "deep time." Deep time or geologic time appears to be one of the fundamental and problematic concepts for the understanding of evolution (see, for example, Dodick and Orion 2003a, b, c). In order to understand evolutionary processes, we also need to understand the temporal framework of evolution. Gould (1987) described the problem with understanding deep time in his book Time's Arrow, Time's Cycle. According to Gould (1987 p. 2, 3):

Deep time [is] so difficult to comprehend, so outside our ordinary experience, that it remains a major stumbling block to our understanding. [...] An abstract, intellectual understanding of deep time comes easily enough-I know how many zeroes to place after the 10 when I mean billions. Getting it into the gut is quite another matter. Deep time is so alien that we can really only comprehend it as metaphor. And so we do in all our pedagogy.

Anderson and Wallin (2006) also suggested that evolutionary time should be made concrete, for example, by using the school's longest corridor as a metaphor for deep time. However, other research suggests that the use of metaphors is not enough to solve the problem that students have with grasping the concept of deep time.

The number of studies concerning learners' conceptions of deep time is limited (Dodick and Orion 2003a, b; Trend 2000, 2001). Within the framework of a research program on the understanding of geological time across society, Trend (2000, 2001) observed that students and teachers have difficulties in grasping the concept of deep time. The results of his study (Trend 2001) suggest that primary teachers and students appear to perceive geologic time as consisting of several broad time categories and that learners are more comfortable with relative time (ranking geo-events in relation to other events) than absolute time (actual date of an event) within the context of deep time. The huge numbers used to describe absolute time seem to cause confusion with students. Trend (2001) suggested that a curriculum for geoscience should, therefore, be developed based on a sequence of pivotal geo-events, events in the history of life such as: the first occurrence of life on earth; the first life with hard parts; the first fish, land animals, trees, birds, and humans; and the extinction of the trilobites and dinosaurs. Students should be taught to place a selection of these pivotal events into correct periods of time with an emphasis on dates and duration.

The studies by Evans and Trend are first indications that a natural history perspective might provide a good context for understanding micro-evolutionary processes. Evans' study suggests that exposure to evidence that animals can change allows children to develop evolutionary explanations for the origin of species. Trend's study suggests that the inclusion of narratives of unique historical events within the teaching of biology can enable students to acquire an understanding of deep time and, thus, provide students with a temporal framework for micro-evolutionary processes.

\section{Conclusion and Outlook}

Within the framework of this article, we focused attention on evolution in the sense of evolutionary history as a unifying theme for biology education. We argued that the 
different topics within biology education should be enriched with a natural history perspective. Our hypothesis is that the integration of historical narratives in biology teaching enables teachers to connect the different biological topics to one another and to create a context for an understanding of micro-evolutionary processes. While there are some indications that a natural history perspective can function as a context for understanding micro-evolutionary processes like natural selection, more research is called for. Empirical studies on students' understanding of evolutionary theory should, therefore, include "history of life" concepts like "deep time" and "MRCA." We really need to learn more about the relationship between students' understanding of adaptation and their understanding of deep time and MRCA. We find that the historical nature of biology should be given more attention within biology education and research thereof and that the time has come to find out what a historical perspective can contribute to biology teaching.

Acknowledgement We thank Thomas Reydon for feedback on earlier drafts of this paper.

\section{References}

Alters BJ, Nelson GE. Perspective: teaching evolution in higher education. Evolution Int J Org Evolution. 2002;56:1891-901.

Alvarez LW, Alvarez W, Asaro F, Michel HV. Extraterrestrial cause for the Cretaceous-Tertiary extinction. Science. 1980;208:1095108. doi:10.1126/science.208.4448.1095.

Anderson B, Wallin A. On developing Content-oriented Theories taking biological evolution as an example. Int J Sci Educ. 2006;28:673-95. doi:10.1080/09500690500498385.

Baalmann W, Frerichs V, Kattmann U. How the gorillas became darkresearch in students' conceptions leads to a rearrangement of teaching genetics and evolution. In: De Jong O, Kortland K, Waarlo AJ, Buddingh J, editors. Bridging the gap between theory and practice: What research says to the science teacher. Proceedings of the 1998 International Summer Symposium Utrecht University, The Netherlands. Hong Kong: ICASE; 1999. p. 171189.

Baum DA, DeWitt-Smith S, Donovan SSS. The tree-thinking challenge. Science. 2005;310:979-80. doi:10.1126/science.1117727.

Baumann B, Harwardt M, Schoppe S, Kattmann U. Vom Wasser aufs Land-und zurück. Unterricht Biol. 1996;218:17-21.

Beatty J. The evolutionary contingency thesis. In: Wolters G, Lennox JG, editors. Concepts, theories, and rationality in the biological sciences. Pittsburgh, PA: Pittsburgh University Press; 1995. p. $45-81$.

Boersma KT, Van Graft M, Harteveld A, De Hullu E, De Knecht-van Eekelen A, Mazereeuw M, et al. Leerlijn biologie van 4 tot 18 jaar: Uitwerking van de concept-contextbenadering tot doelstellingen voor het biologieonderwijs. Utrecht: CVBO; 2007.

Bowler PJ. Evolution: The history of an idea. Berkeley: University of California Press; 2003.

BSCS. Biology teachers' handbook. New York: Wiley; 1963.

BSCS. Developing Biological Literacy: A guide to developing secondary and post-secondary biology curricula. Dubuque: Kendall/Hunt; 1993.
Catley KM. Darwin's missing link-A novel paradigm for evolution education. Sci Educ. 2006;90:767-83. doi:10.1002/sce. 20152.

Cowie J. Climate Change: Biological and human aspects. Cambridge: Cambridge University Press; 2007.

Dagher ZR, Boujaoude S. Students' perceptions of the nature of evolutionary theory. Sci Educ. 2005;89:378-91. doi:10.1002/ sce. 20054.

Darwin C. On the origin of species by means of natural selection, or the preservation of favoured races in the struggle for life (facsimile of the first edition). Cambridge: Harvard University Press; 1964.

Dobzhansky T. Nothing in biology makes sense except in the light of evolution. Am Biol Teach. 1973;35:125-9.

Dodick J, Orion N. Measuring student understanding of geologic time. Sci Educ. 2003a;87:708-31. doi:10.1002/sce.1057.

Dodick J, Orion N. Cognitive factors affecting student understanding of geologic time. J Res Sci Teach. 2003b;40:415-42. doi:10.1002/tea.10083.

Dodick J, Orion N. Introducing evolution to non-biology majors via the fossil record: A case study from the Israeli high school system. Am Biol Teach. 2003c;65:185-90. doi:10.1662/00027685(2003)065[0185:IETNMV]2.0.CO;2.

Evans EM. The emergence of beliefs about the origin of species in school-age children. Merrill-Palmer Q. 2000;46:221-54.

Futuyma DJ. Wherefore and whither the naturalist? Am Nat. 1998;151:1-6. doi:10.1086/286097.

Futuyma DJ, editor. Evolution, science and society: evolutionary biology and the national research agenda. New Brunswick (NJ), Rutgers University; 1999.

Futuyma DJ. Evolution. Sunderland, MA: Sinauer; 2005.

Gelman SA. The essential child: Origins of essentialism in everyday thought. Oxford: Oxford University Press; 2003.

Goudge TA. The Ascent of life. Toronto: The University of Toronto Press; 1961.

Gould SJ. Time's arrow, time's cycle: Myth and metaphor in the discovery of geologic time. Cambridge, MA: Harvard University Press; 1987.

Gould SJ. Wonderful life: The Burgess Shale and the nature of history. New York: Norton; 1989.

Gould SJ. The structure of evolutionary theory. Cambridge: Belknap/ Harvard; 2002.

Gregory TR. Understanding evolutionary trees. Evolution. Educ Outreach. 2008;1:121-37. doi:10.1007/s12052-008-0035-x.

Griffiths PE. In what sense does 'nothing make sense except in the light of evolutions'? Acta Biotheor. 2009; In press.

Hempel GC. Explanations in science and in history. In: Fetzer JH, editor. The philosophy of Carl G. Hempel: Studies in science, explanation and rationality. New York: Oxford University Press; 1963.

Hull DL. Science as a Process. Chicago: University of Chicago Press; 1988.

Hull DL. Model of scientific explanation. In: Nitecki MH, Nitecki DV, editors. History and evolution. Albany: State University of New York Press; 1992. p. 69-80.

Jablonka E, Lamb MJ. Evolution in four dimensions: Genetic, epigenetic, behavioral, and symbolic variation in the history of life. Cambridge: MIT press; 2005.

Jardine N, Secord JA, Spary EC, editors. . Cultures of natural history. Cambridge: Cambridge University Press; 1996.

Kattmann U. Konzeption eines naturgeschichtlichen Biologieunterrichts: Wie Evolution Sinn macht. ZfDN. 1995;1:29-42.

Kattmann U. Aquatics, Flyers, Creepers and Terrestrials-students' conceptions of animal classification. J Biol Educ. 2001;35:141-7.

Kattmann U. Bioplanet Erde: Erdgeschichte ist Lebensgeschichte. Unterricht Biol. 2004;299:4-13. 
Kelemen D. Function, goals and intention: Children's teleological reasoning about objects. Trends Cogn Sci. 1999;3:461-8. doi:10.1016/S1364-6613(99)01402-3.

Kelemen D. Britisch and American childrens' preferences for teleofunctional explanations of the natural world. Cognition. 2003;88:201-21. doi:10.1016/S0010-0277(03)00024-6.

KNAW. Biologieonderwijs: een vitaal belang. Amsterdam: KNAW; 2003.

Bildungsstandards KMK. im Fach Biologie für den Mittleren Schulabschluss. http://www.kmk.org/schul/Bildungstandards/ Biology_MSA_16-12-04.pdf. (2004).

Margulis L. Symbiosis in cell evolution. San Francisco: Freeman; 1981.

Mayr E. The growth of biological thought: Diversity, evolution, and inheritance. Cambridge: Belknap/Harvard; 1982.

Mayr E. This is biology: The science of the living world. Cambridge: Belknap/Harvard; 1997.

Meir E, Perry J, Herron JC, Kingsolver J. College students' misconceptions about evolutionary trees. Am Biol Teach. 2007;7:71-6. doi:10.1662/0002-7685(2007)69[71:CSMAET]2.0.CO;2.

Nagel E. The structure of science: Problems in the logic of scientific explanation. New York: Harcourt, Brace \& World; 1961.

National Academy of Sciences. Teaching about evolution and the nature of science. Washington, DC: National Academy Press; 1998.

Novick LR, Catley KM. Interpreting hierarchical structure: Evidence from cladograms in biology. In: Barker-Plummer D, Cox R, Swoboda N, editors. Diagrams 2006, LNAI 4045. Berlin Heidelberg: Springer; 2006. p. 176-180.

Novick LR, Catley KM. Understanding phylogenies in Biology: The influence of a gestalt perceptual principle. J Exp Psychol Appl. 2007;13:197-233. doi:10.1037/1076-898X.13.4.197.

O'Hara RJ. Homage to Clio, or, towards an historical philosophy for evolutionary biology. Syst Zool. 1988;37:142-55. doi:10.2307/ 2992272.

O'Hara RJ. Population thinking and tree thinking in systematics. Zool Scr. 1997;26:323-9. doi:10.1111/j.1463-6409.1997.tb00422.x.

Osborne J, Dillon J. Science education in Europe: critical reflections. A report to the Nuffield Foundation. London: Nuffield Foundation; 2008.
Poling DA, Evans EM. Why do birds of a feather flock together? Developmental change in the use of multiple explanations: intention, teleology and essentialism. Br J Dev Psychol. 2002;20:89-112. doi:10.1348/026151002166343.

Ridley M. Evolution (second edition). Cambridge, MA: Blackwell Science; 1996.

Rudolph JL, Stewart J. Evolution and the nature of science: On the historical discord and its implications for education. J Res Sci Teach. 1998;35:1069-89. doi:10.1002/(SICI)1098-2736(199812) 35:10<1069::AID-TEA2>3.0.CO;2-A.

Salmon WC. Four decades of scientific explanation. In: Kitcher P, Salmon WC, editors. Minnesota studies in the philosophy of science:, vol. XIII. Scientific explanation Minneapolis: University of Minnesota Press; 1989. p. 3-219.

Sander E, Jelemenská P, Kattmann U. Woher kommt der Sauerstoff? Überlegungen zum erdgeschichtlich-biologischen Ungleichgewicht. Unterricht Biol. 2004;299:20-4.

Skelton P, editor. . Evolution: A biological and Palaeontological Approach. Workingham, England: Addison Wesley; 1993.

Sober E. Reconstructing the past: parsimony, evolution, and inference. Cambridge, MA: MIT Press; 1988.

Thewissen JGM, Bajpai S. Whale origins as a poster child for macroevolution. Bioscience. 2001;51:1037-49. doi:10.1641/ 0006-3568(2001)051[1037:WOAAPC]2.0.CO;2.

Trend RD. Conceptions of geologic time among primary teacher trainees, with reference to their engagement with geoscience, history, and science. Int J Sci Educ. 2000;22:539-55. doi:10.1080/095006900289778.

Trend RD. Deep Time Framework: A preliminary study of U.K. primary teachers' conceptions of geologic time and perceptions of geoscience. J Res Sci Teach. 2001;38:191-221. doi:10.1002/ 1098-2736(200102)38:2<191::AID-TEA1003>3.0.CO;2-C.

Weiner J. The beak of the finch: A story of evolution in our time. New York: Vintage Books; 1994.

Zetterqvist A. Teachers' views on their teaching of evolution. In: Bayrhuber H, Brinkman F, editors. What-Why-How? Research in Didaktik of Biology. Proceedings of the first conference of European Researchers in Didaktik of Biology (ERIDOB). Kiel: IPN; 1999. p. 11-20. 